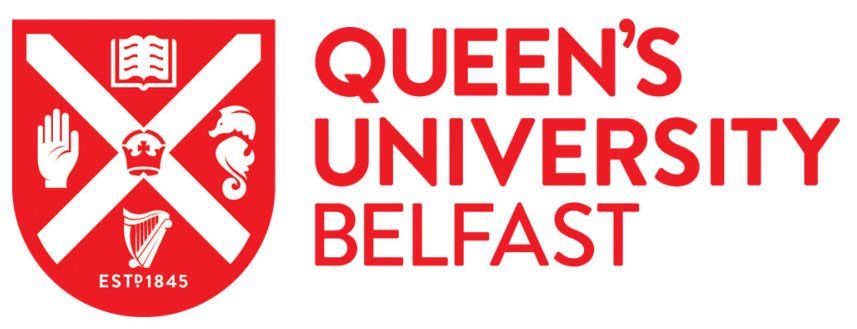

\title{
Heritability estimation via molecular pedigree reconstruction in a wild fish population reveals substantial evolutionary potential for sea-age at maturity, but not size within age-classes
}

Reed, T. E., Prodöhl, P., Bradley, C., Gilbey, J., McGinnity, P., Primmer, C. R., \& Bacon, P. J. (2018). Heritability estimation via molecular pedigree reconstruction in a wild fish population reveals substantial evolutionary potential for sea-age at maturity, but not size within age-classes. Canadian Journal of Fisheries and Aquatic Sciences. https://doi.org/10.1139/cjfas-2018-0123

\section{Published in:}

Canadian Journal of Fisheries and Aquatic Sciences

Document Version:

Peer reviewed version

Queen's University Belfast - Research Portal:

Link to publication record in Queen's University Belfast Research Portal

\author{
Publisher rights \\ (c) 2018 Canadian Science Publishing. This work is made available online in accordance with the publisher's policies. Please refer to any \\ applicable terms of use of the publisher.
}

\section{General rights}

Copyright for the publications made accessible via the Queen's University Belfast Research Portal is retained by the author(s) and / or other copyright owners and it is a condition of accessing these publications that users recognise and abide by the legal requirements associated with these rights.

Take down policy

The Research Portal is Queen's institutional repository that provides access to Queen's research output. Every effort has been made to ensure that content in the Research Portal does not infringe any person's rights, or applicable UK laws. If you discover content in the Research Portal that you believe breaches copyright or violates any law, please contact openaccess@qub.ac.uk. 


\section{Heritability estimation via molecular pedigree reconstruction in a}

\section{2 wild fish population reveals substantial evolutionary potential for}

3 age at maturity, but not size within age-classes.

4 Can. J. Fish. Aq. Sci.

Acceptance date: 08-Jul-2018

5

6 Thomas E Reed ${ }^{1 \dagger^{*}}$, Paulo Prodöhl ${ }^{2 \dagger}$, Caroline Bradley $^{2}$, John Gilbey ${ }^{3}$, Philip McGinnity ${ }^{1,4}$,

$7 \quad$ Craig R. Primmer ${ }^{5,6}$, and Philip J. Bacon ${ }^{3}$.

8

$9{ }^{1}$ School of Biological, Earth and Environmental Sciences, University of Cork, North Mall, 10 Cork, Ireland.

$11{ }^{2}$ Institute for Global Food Security, School of Biological Sciences, Queen's University of 12 Belfast, Medical Biology Centre, 97 Lisburn Road, Belfast, BT9 7BL, UK.

$13{ }^{3}$ Marine Scotland Science, Freshwater Laboratory, Faskally, Pitlochry, Perthshire PH16

14 5LB, Scotland, UK.

$15{ }^{4}$ Marine Institute, Furnace, Newport, Co. Mayo, Ireland.

$16{ }^{5}$ Department of Biosciences, University of Helsinki, 00014, Finland

$17{ }^{6}$ Institute of Biotechnology, University of Helsinki, 00014, Finland

$18 \dagger$ Joint first authors.

$19 *$ Corresponding author: treed@ucc.ie 


\section{ABSTRACT}

22 While evolutionary responses require heritable variation, estimates of heritability $\left(h^{2}\right)$ from

23 wild fish populations remain rare. A 20-year molecular pedigree for a wild Scottish population of Atlantic salmon (Salmo salar) was used to investigate genetic contributions to (co)variation in two important, correlated, phenotypic traits: "sea-age" (number of winters spent at sea prior to spawning) and size-at-maturity (body length just prior to spawning). Seaage was strongly heritable $\left(h^{2}=0.51\right)$ and size exhibited moderate heritability $\left(h^{2}=0.27\right)$. A very strong genetic correlation $\left(r_{G}=0.96\right)$ between these traits implied the same functional loci must underpin variation in each. Indeed, body size within sea-ages had much lower heritability that did not differ significantly from zero. Thus, within wild $S$. salar populations, temporal changes in sea-age composition could reflect evolutionary responses, whereas rapid changes of body-size within sea-ages are more likely due to phenotypic plasticity. These inheritance patterns will influence the scope of evolutionary responses to factors such as harvest or climate change and, hence, have management implications for salmonid populations comprising a mix of sea ages. adaptation, management, conservation genetics 
Life history traits such as age and size at first reproduction are typically expected to be under strong selection, given their close links with Darwinian fitness (Stearns 1992, Roff 2002). All else being equal, genotypes that reproduce as early as possible in life should have higher relative fitness than those that first reproduce at older ages (Brommer et al. 2002). In species with indeterminate growth such as most fishes, however, there may be strong breeding advantages (especially for females) to delaying first reproduction to older ages, and hence larger sizes (Heino and Kaitala 1999). The optimum age and size at first reproduction will then depend on factors such as (seasonal) environmental opportunities for growth, agespecific extrinsic mortality schedules, and the extent to which reproductive success depends on body size (Stearns 1992, Charlesworth 1994, Roff 2002). Human-induced changes to any of these parameters can alter the selective pressures on populations; for example, harvests of wild animals can drive "unnatural selection" on phenotypic traits such as age at maturity and body size (Allendorf and Hard 2009, Heino et al. 2015, Harvey et al, 2017), while climate change can impact selective dynamics in a range of complex ways (Munday et al. 2013, Sydeman et al. 2015). Inferring the potential for evolutionary responses, however, requires information on the extent to which observed phenotypic (co)variation is underpinned by genetic (co)variation (Kuparinen and Hutchings, 2017). Detailed, long-term, studies of naturally regulated populations, in which the life histories, reproductive success and pedigrees of individual animals are measured or inferred can provide this information (Naish and Hard 2008, Clutton-Brock and Sheldon 2010).

In Atlantic salmon (Salmo salar L.) and other salmonid fishes, the sea-age of adults returning to spawn for the first time is an important trait from both ecological and economic perspectives, as older fish tend to be larger and therefore more valuable from a commercial and recreational fishing perspective, while also having higher fecundity and therefore 
contributing more towards total annual egg numbers. Sea-age variation may also contribute towards ecological and evolutionary portfolio effects via bet-hedging mechanisms (Schindler et al., 2015), where risk is spread across multiple sea-age cohorts. Some individuals, and populations of Atlantic salmon, return after just one winter at sea (1SW), whereas others known as multi-sea winter (MSW) fish return after two or more winters at sea (Klemetsen et al, 2003). The marine feeding destination, sea-age, adult-return size and adult run-timing are all inter-related (Malcolm et al, 2010). The average size of returning adults generally increases with time spent at sea, both across and within sea-age classes; for example, MSW fish tend to be on average much larger than $1 \mathrm{SW}$, and later-running fish of a given sea-age class are typically larger than early-running fish (Hutchings \& Jones 1998, Bacon et al. 2009, 2010, Barson et al. 2015). A substantial genetic component underlying sea-age variation has been shown or implied by several studies of Atlantic salmon (Nævdal 1983, Gjerde 1984, Johnston et al. 2014, Ayllon et al. 2015, Barson et al. 2015) and related species such as Chinook salmon (Oncorhynchus tshawytscha) (Hankin et al. 1993, Quinn et al. 2001) and steelhead/rainbow trout (Oncorhynchus mykiss) (Tipping 1991, Kause et al. 2003).

Body-length at maturity has also been shown to be heritable in salmonids generally, with Carlson \& Seamons (2008) reporting a median heritability (the fraction of phenotypic variation explained by genetic variation) estimate of 0.21 across six salmonid studies. Only one of these studies (Dickerson et al. 2005), however, involved a situation where the fish (in that case, pink salmon, Oncorhynchus gorbuscha) spawned and reared naturally in a wild river environment; the rest all involved either hatchery/farm-origin broodstock and/or artificial rearing conditions (Carlson and Seamons 2008). Since then a limited number of additional salmonid studies have appeared that estimate heritability of length-at-age in freshwater in fully natural environments (Serbezov et al. 2010, Morrissey and Ferguson 2011, 
93 Reed et al. 2015), but these studies did not focus on heritability of size-at-maturity

94

95

96

97

98

99

100

101

102

103

104

105

106

107

108

109

110

111

112

113

114

115 specifically.

Availing from the (still rare) existence of a multi-generation data set from a wild Atlantic salmon population, the specific aims of this study were to: (1) construct a pedigree based on molecular data, (2) estimate the heritability of both adult body-length and sea-ageat-maturity; (3) test for any genetic correlation between these traits; and (4) test for temporal trends in estimated breeding values for both traits, which would indicate microevolutionary responses over the study period. Significant phenotypic trends in body size and sea-age are apparent in this population during our 1991-2011 study period (Glover, pers comm.) and other populations in the region more generally (Bacon et al. 2009), but it remains unknown whether there is any genetic component to these trends. Answering the latter question could suggest fruitful new avenues for research and interpretation of monitoring data.

\section{METHODS}

\section{Study site}

The Girnock Burn (Fig.1) is an intensively studied upland catchment of c. $30 \mathrm{~km}^{2}$ on the Aberdeenshire Dee (confluence $57^{\circ} 0.6^{\prime} \mathrm{N}, 3^{\circ} 5.3^{\prime} \mathrm{W}$ ), in north-eastern Scotland, which has been operated by Marine Scotland Science Freshwater Fisheries Laboratory since 1966. Full details of the site, monitoring data and a list of associated publications are available at URL1. In brief, the catchment contains some $8 \mathrm{~km}$ of nursery stream for Atlantic salmon ranging in altitude from 230 to $900 \mathrm{~m}$. Adult salmon entering the Girnock are caught in an ascending trap near the confluence with the mainstem of the Aberdeenshire Dee, given an individual identification (floy) tag, sexed based on phenotypic characteristics, measured (adult fork 
body-length, hereafter body-length) and aged by scale-reading, following international

117 protocols.

118 Apart from unusual scale- or tissue-sample loss, the DNA samples obtained from adults can

119 be taken as a complete set of breeders (only one adult is known to have got above the traps without being caught in 50 years, during emergency trap-maintenance during an autumn spate). Since the early 1990s tissue samples (adipose-fin clips) of adults were also taken, and stored in molecular grade (99\%) ethanol.

The Girnock provided an example of a fully wild Atlantic salmon population from the start of the historic study (1966) until 1999, with adult fish being allowed to spawn naturally above the traps. During the late 1990 s, numbers of adult females fell very low $(9,11 \& 22$ over three years), and from 2000 to 2010 increasing proportions of adults were temporarily held, stripped and their eggs stocked into the river section above the trap (see Bacon et al. 2015; URL2; Glover, pers. comm.). The fish were artificially mated with a crossing protocol designed to increase mating variation and promote the maintenance of broad genetic variation (see Bacon et al. 2015 for full details). From 2011 the system was returned to fully natural spawning (but no offspring from that period returned during this study). Most juveniles from the Girnock undergo parr-to-smolt transformation and seaward migration at age 2+ (third year of life) or $3+$ (fourth year of life). A minority of adults return after $1 \mathrm{SW}$, the majority after 2SW, typical of upland Scottish salmon sites (Gurney et al. 2015; URL3). 3SW adults are now uncommon, and repeat spawners are regionally relatively rare (less than $2 \%$, as is typical for eastern Scotland, Bacon et al. 2012). The life span of Atlantic salmon from the

137 Girnock is therefore typically 5 to 6 years, but can range from 4 to 8 years. 1 SW adults typically suffer only about half the marine mortality of $2 \mathrm{SW}$ fish, but, being around half the size (biomass), female $1 \mathrm{SW}$ salmon produce about half as many eggs as $2 \mathrm{SW}$ females (Gurney et al. 2012, 2015). 
DNA samples were derived from three sources during our study period 1991-2011. In the mid-1990s, aliquots of genomic DNA extracted during earlier studies were available, prepared according to protocols given in Taggart et al. (2001). Most of the other samples from the late 1990s onwards were obtained from adipose fin-clips taken from adults, stored in molecular grade (99\%) ethanol, and with genomic DNA extracted using the Promega,

Wizard $®$ SV 96 Genomic DNA Purification System (www.promega.com) (see Keenan et al. 2013a). The remaining samples, mainly from the early 1990s, plus some fish that were not adipose-clipped in later years, were obtained from scale samples, archived in paper packets, air-dried and with the genomic DNA extracted as above. Genomic DNA for all samples was checked for quality and concentration through visual comparison with a HindIII digested $\Lambda$ DNA size standard on Ethidium Bromide stained 0.8\% 0.5X TBE agarose gels.

All samples were examined for a panel consisting of 17 putatively neutral microsatellite marker loci organised in two multiplex PCR. These microsatellites were selected based on information content (polymorphism), consistent co-amplification reliability and non-overlapping size compatibility. Multiplex- 1 comprised ten markers and Multiplex 2 consisted of the seven remaining microsatellites (see Appendix A for details); , in addition to a sex specific marker based on the sdY locus, which is a conserved region for sex determination in salmonids (Yano et al. 2012, 2013). This later marker was used to doublecheck concordance between the biometric records and the genotype results (to guard against recording errors, including samples potentially omitted from sequences). 
of ABI fluorescent labelled forward and/or unlabelled reverse 'pig' tailed PCR primers

(Appendix A.1 for details on labelled and unlabelled primers, and specific primer concentrations per marker loci). Samples were overlain with $10 \mu \mathrm{l}$ of mineral oil to prevent evaporation. Thermocycling conditions for both multiplex panels were as follows: an initial denaturation step of $15 \mathrm{~min}$ at $95^{\circ} \mathrm{C}$, followed by 28 cycles of $95^{\circ} \mathrm{C}$ for $30 \mathrm{sec}, 57^{\circ} \mathrm{C}$ for 90 sec and $72^{\circ} \mathrm{C}$ for $60 \mathrm{sec}$. This was followed by a final extension step of $30 \mathrm{~min}$ at $60^{\circ} \mathrm{C}$. All reactions were carried out using Techne TC-Plus thermal cyclers, with a heated lid at $105^{\circ} \mathrm{C}$. Amplified fragments were diluted one-tenth with double-distilled $\mathrm{H}_{2} \mathrm{O}$, and $1 \mu \mathrm{l}$ of this dilution was added to $9 \mu \mathrm{l}$ of HiDi formamide (Thermo Fisher Scientific) mixed with Gene Scan 600-LIZ size ladder (Thermo Fisher Scientific).

Diluted PCR products were analysed on a 96 capillary ABI 3730XL DNA analyser (Thermo Fisher Scientific), and the fragment size analysis (i.e. allelic calls) for genotypes carried out using GENEMAPPERv4.1 (Thermo Fisher Scientific). Genotypes for each microsatellite locus/specimen were individually checked and manually confirmed prior to their addition to an electronic database. Over $50 \%$ of the genotyping was independently repeated to ensure consistent scoring (i.e. to minimise scoring errors). Locus-specific statistics including allele numbers, heterozygosity, allelic richness and deviations from Hardy-Weinberg expectations were estimated both on annual caught samples (i.e. candidate parents) and the pooled data set using the R package diveRsity (Keenan et al. 2013b). The power of the markers to correctly assign individuals to unique families was carried out using Family Assignment Program (FAP; Taggart 2007).

Pedigree reconstruction 
Parental cohorts were defined as adults returning to spawn at the Girnock in each autumn. For each such spawning cohort, a sub-set of later returning adults that comprised the full span of their sea-going progeny, by all possible river-age (1 to 4 ) and sea-age (1 to 3 ) range combinations, was assembled as putative offspring. For instance, returning adults caught in the trap between 1993 and 1998 were analysed as putative offspring for the 1991 spawning cohort. Pedigree reconstruction was carried out using FAP (Taggart 2007), which estimates exclusion-based family assignment probabilities within family mixtures where all parental genotypes are known. In summary, FAP was used to search all potential offspring for the given spawning cohort and to exclude those that could not derive from a given putative pair of male and female adult parents (based on field-observed sexes). The output was a list of 'family-trio' identities (potential female parent, male parent, offspring), together with information on the number of loci matching exactly, the number of evidently mismatching loci, and the list of such mismatching offspring loci. This process was repeated, separately, for each adult cohort from 1991 to 2006 (i.e. for all spawning cohorts for which full-sets of putative returning adult offspring were available in the sample database). and any mismatching loci for the putative offspring and its parents were double checked back to the original ABI raw chromatogram data. Most allele mismatches involved single marker loci and resulted from one individual (one parent or the offspring) being incorrectly assigned an adjacent-sized allele, rather than the likely-true parental one. These could be easily rectified following visual inspection. Following this second stage of quality control, the validated family trios were used as the basis for the pedigree. Only complete parent-offspring records were used in this study (a sampled offspring and both its anadromous father and mother), excluding any offspring with only one known adult female parent, presumably sired by an un-sampled precocious parr male. FAP was also used to estimate the 'parental 
exclusion power' of the data (i.e. power of the markers to correctly assign individuals to a given set of known families).

Power analyses for heritability estimation

In order to quantify the statistical power in this dataset to detect true non-zero $h^{2}$, a power analysis (see Appendix B.3 for full details) was conducted in which a range of $h^{2}$ values were simulated $\left(h^{2}=0.05,0.10,0.15,0.20,0.25,0.30,0.40,0.50,0.75\right)$ using the $r b v$ function in MCMCglmm (Hadfield 2010). One thousand replicate simulations were run for each simulated $h^{2}$ value, and each time the estimated $h^{2}$ and its associated P-value based on likelihood ratio tests were returned and saved. Power was then calculated as the proportion of P-values that were $<0.05$.

\section{Estimation of quantitative genetic parameters using animal models}

Bayesian animal models were used to estimate quantitative genetic parameters of interest using the R package MCMCglmm (Hadfield 2010). Full details on the estimation procedures for the quantitative genetic parameters, as well as more details on the pedigree structure, are given in Appendix B.1

Univariate animal models for the data were first devised (one trait as a single response variable) to estimate the narrow-sense heritability $\left(h^{2}\right)$ of each of the phenotypic traits of interest: adult body-length and sea-age-at-maturity. These univariate models partitioned the total phenotypic variance $V_{\mathrm{P}}$ in each trait into contributions from additive genetic effects $\left(V_{\mathrm{A}}\right)$, maternal effects $\left(V_{\mathrm{M}}\right)$, year effects $\left(V_{Y}\right)$ and residual effects $\left(V_{R}\right)$, the latter assumed to arise from environmental effects and non-additive genetic effects. Thus $V_{\mathrm{P}}=V_{\mathrm{A}}+V_{\mathrm{M}}+V_{\mathrm{Y}}+$ 
$V_{\mathrm{R}}$, and $h^{2}=V_{\mathrm{A}} / V_{\mathrm{P}}$. A fixed effect of sex (two level factor: adult males and adult females)

237

238 was included in the univariate models for both traits, to control for the fact that males may mature at a younger age, on average, and hence also are smaller as adults, than females. Yearto-sea (the year the focal individual migrated to sea as a smolt, known from scale readings) was used to define temporal cohorts (i.e. $V_{\mathrm{Y}}$, see Appendix B.2).

Adult body size (measured in centimetres and treated as a Gaussian variable) was first natural logarithm (hereafter simply log) transformed before fitting the animal models, as preliminary exploratory analyses indicated that this transformation minimised autocorrelation between MCMC samples and yielded less skewed posterior distributions of the parameters.

In Atlantic salmon, among-individual variation in adult body size is strongly affected by sea-age, as fish that remain at sea an extra year have more time for marine growth. The mean size of $1 \mathrm{SW}$ salmon in our 1990-2012 sample, for example, was $55.8 \pm 2.1$ (S.E.) cm, whereas the mean size of MSW salmon was $68.4 \pm 2.1 \mathrm{~cm}$. If sea age itself is heritable (i.e. if the propensity to stay $>1$ year at sea has a genetic basis), then the $h^{2}$ of adult body size as estimated from a univariate animal model will conceptually encompass the effects of genes influencing sea age (which in turn drive size variation among sea-age classes), as well as, genes influencing body size variation within sea-ages. To capture this heritable effect, a new variable "sea-age-corrected body-length", $\left(\right.$ denoted $\left.\hat{S}_{i, a}\right)$, was constructed as follows:

$$
\hat{S}_{i, a}=S_{i, a}-\bar{S}_{a},
$$

where $S_{i, a}$ corresponds to the log body-length of individual $i$ of sea-age category $a$ (1SW or MSW) and $\bar{S}_{a}$ is the mean log-body-length of all individuals of sea-age $a$. A univariate animal model of $\hat{S}_{i, a}$ was then run (UV model 2) with the same MCMCglmm settings and model structure as UV model 1 to estimate $h^{2}$ of body-length conditional on sea-age. 

maturation after one sea-winter and a value of 1 to maturation after two or more sea-winters (178 of the records in the dataset were 1SW adults; among the MSW adults, only 5 out of 323 spent three winters at sea, and only one fish spent four winters at sea). A probit link function (family = "threshold" in MCMCglmm) was used, where the resulting residual variance refers to the variance of the link function, here fixed at 1 in order to render $V_{A}$ estimable. The $h^{2}$ reported from this univariate model of sea-age (UV model 3) thus refers to $h^{2}$ on the liability scale, rather than the observed binary scale (see Appendix B.2).

In the next step, bivariate animal models (both traits included as response variables) were used to partition the overall phenotypic (co)variance between body-length and sea-ageat-maturity into additive genetic versus environmental (residual) components. Maternal effects and year effects were not included in these models (see Appendix B.1). In the first bivariate animal model (BV model 1), trait 1 was log adult body-length and trait 2 was binary sea-age. Unstructured covariance matrices for the random effects were specified, in order to provide estimates of $\mathrm{COV}_{\mathrm{A}}$ and the residual covariance, $\mathrm{COV}_{\mathrm{R}}$. The additive genetic correlation $\left(r_{\mathrm{G}}\right)$ between body-length and sea-age was calculated by dividing $\mathrm{COV}_{\mathrm{A}}$ by the product of the square root of $V_{\mathrm{A}}$ for each trait. Similarly, the environmental (residual) correlation $\left(r_{\mathrm{E}}\right)$ was calculated by dividing the residual covariance by the product of the square root of $V_{\mathrm{R}}$ for each trait. Statistical support for $r_{\mathrm{G}}$ and $r_{\mathrm{E}}$ was assessed by checking whether the $95 \%$ highest posterior density (HPD) interval for each included zero. response variables were sea-age-corrected body length (on the log scale, i.e. $\hat{S}_{i, a}$ ) and sea-age. This effectively corrected adult body size for variation due to sea-age, and the resulting $r_{\mathrm{G}}$ and $r_{\mathrm{E}}$ estimates from $\mathrm{BV}$ model 2 correspond to the genetic and environmental correlations (respectively) between "body size-within-sea-age" and sea age. 
284 All quantitative genetic parameter estimates are reported as posterior means \pm HPD intervals.

Testing for microevolutionary trends

288 In a quantitative genetic sense, microevolutionary responses are apparent when estimated breeding values (estimates of the additive genetic "merit" of an individual for a given trait) exhibit a temporal trend at the population level. We used the procedure recommended by Hadfield et al. (2010 b) to test for evolutionary change in body-length corrected for sea-age, and in sea-age itself (see Appendix B.4 for full details).

\section{RESULTS}

\section{Population composition and phenotypic trends}

296

297

298

During our 1991-2011 study, a total of 1,733 anadromous adults came to the Girnock to spawn [annual average 75.3 (range 29 to 144, total adults)], of which the great majority ( $97 \%$, range $88 \%$ to $100 \%$ ) in every year, were of known sex, sea-age and river-age. The annual proportion of returning adults that had prior-clipped adipose fins, indicating that they were both reared above the Girnock trap and trapped as juvenile emigrants, averaged $47 \%$ (range $31 \%$ to $76 \%$ ). The remaining $53 \%$ of unclipped returning adults are assumed to have either: 1) passed over the smolt trap and not been marked; or, more likely, (2) to have been reared below the Girnock trap. If reared below the Girnock trap, they were probably reared outside of the Girnock catchment (only $18 \%$ of fully-grown parr are estimated to be reared within the Girnock catchment but also below the Girnock trap, a region comprising just $8 \%$ of the Girnock's wetted area (Glover pers comm.)). An annual average of $47 \%$ of known-sex 
adults were females (range $30 \%$ to $60 \%$; male $\% \approx 100 \%$ - female $\%$ ). During the sub-period of ova-manipulation (2000 to 2010) an average of $80 \%$ of females (range $48 \%$ to $100 \%$ ) were artificially spawned. Fluctuations and/or trends in population numbers and composition occurred (see Discussion).

\section{Molecular genetics and pedigree reconstruction}

313 The rate of genotyping success was high, with $92 \%$ of all individual samples amplifying for at least 14 or more marker loci (i.e. $82 \%$ of screened markers per sample). Full genotype information (17 loci) was obtained for $83 \%$ of all samples screened. Loci summary statistics are detailed in Appendix A.2. Across the 17 loci, excluding the sex marker, there were, on average across the 20 cohorts, 11.5 alleles per locus per year ( \pm 7.9 S.D., range 2 to 47$)$. Within annual cohorts, observed heterozygosity values averaged 0.748 across loci per year $( \pm$ 0.178 S.D., range 0.150 to 1.000 ). Allelic richness within loci was similar over all the study years. There was no evidence for departures from Hardy-Weinberg expectations (HWE) or linkage disequilibrium from any cohort.

Power analysis indicates that the marker panel (17 loci) used provides over $99 \%$ accuracy to identify putative offspring to family. There is only a very minor decrease in power when $14+$ markers are considered with some variation related to the particular marker loci also being noted (i.e. high versus moderately polymorphic marker).

From some 1,600 records of adult genotypes available for paternity assignment during 19912011, 273 full parent-offspring trios (mother, father, offspring) were discerned and retained after quality-controlling. 1991 to 1995 and 2007 to 2011 have records of incomplete families (not all eventual 'older' offspring will have returned and been sampled). Inclusion of such records could bias interpretation of the data. The retained complete parentage-records (both 
parents and all offspring of varying river- and sea-ages) mainly spanned the years 1995 2006; these years happened also to span a period of low returning adult numbers.

Consequently, the estimated annual values of sea-age and body-length are particularly variable.

In order to retain only those parent-offspring trio records that were informative for the quantitative genetic analyses, trios were excluded in which any of the involved individuals were repeat-spawners (i.e. had spawned in previous years); the sex of either parent was unknown; body-length was not measured; or neither sea-age nor river-age were readable from scales (see below). This rigorous filtering reduced the number of useable trios from an initial 336 to 276 (82\% retained).

After such filtering, the years of spawning for both putative parents matched in every case.

342 For one of the 276 trios, a missing value for the offspring's sea-age was estimated based on 343 its year of spawning, its known river-age, and the pedigree-determined year of spawning of its parents. Similarly, for 14 of the 276 trio records, the offspring's river-age was estimated from its year of spawning, its known sea-age, and the pedigree-determined year of spawning of its parents. The offspring's total scale-read age closely matched its pedigree-determined total-age in most cases: in $78 \%$ of cases $(216 / 276$ trios) the match was exact; in $19 \%$ the agecomparisons differed by only a single year (53/276); the remaining seven age-discrepancies comprised four records where age-comparisons differed by 2-years; one at 3-years; and two at 5-years. The latter three records involving offspring-ageing discrepancies of $>2$ years were removed, resulting in 273 rigorously useable parental-trio records.

352 Further details on the pedigree are given in Table 1 and Appendix B.1. 
355 Convergence was good for all animal models (results not shown). The univariate model of body-length (UV model 1) showed that additive genetic effects $\left(V_{A}\right)$ accounted for approximately one-quarter of the total phenotypic variance (Table $2, h^{2}$ of log adult bodylength $=0.27)$. Of the remaining variance (i.e. not including $\left.V_{A}\right)$, maternal effects $\left(V_{M}\right)$ accounted for approximately $13 \%$ ( $9 \%$ of the total phenotypic variance $V_{P}$ ), year-to-sea effects $\left(V_{Y}\right)$ for $15 \%\left(11 \%\right.$ of $\left.V_{P}\right)$ and residual environmental effects $\left(V_{R}\right)$ for $72 \%(53 \%$ of $\left.V_{P}\right)$. Males were on average smaller $(61.62 \pm 0.58 \mathrm{~cm})$ than females $(66.10 \pm 0.33 \mathrm{~cm})$. When body-length was corrected for sea-age (UV model 2), $V_{A}$ then accounted for a considerably smaller fraction of $V_{P}$ (Table $2, h^{2}$ of body length within sea-ages $\left.=0.14\right) . V_{M}$ accounted for approximately $14 \%$ of $V_{P}, V_{Y}$ for $9 \%$, and $V_{R}$ accounted for the remaining $64 \%$. The univariate animal model of sea-age (UV model 3) showed that $V_{A}$ accounted for a little over half of $V_{P}\left(\right.$ Table $2, h^{2}$ of sea-age $\left.=0.51\right)$. Of the remaining variance (i.e. not including $\left.V_{A}\right)$, $V_{M}$ accounted for approximately $10 \%\left(5 \%\right.$ of $\left.V_{P}\right), V_{Y}$ for $44 \%\left(20 \%\right.$ of $\left.V_{P}\right)$ and $V_{R}$ for $46 \%$ $\left(21 \%\right.$ of $\left.V_{P}\right)$.

The results of the bivariate animal model of adult body length and sea-age (BV model 1) mirrored those of the univariate animal models in terms of the estimated heritabilities for the two traits $\left(h^{2}\right.$ of adult body length $=0.26$ and $h^{2}$ of sea-age $=0.48$ in BV model 1 ; Table 3). The estimated genetic correlation between these traits was very high in the bivariate model where body length was not adjusted for sea age $\left(r_{G}=0.96\right.$; Table 3$)$. The results of the bivariate animal model of sea-age-corrected body length and sea-age (BV model 2) also largely mirrored those of the univariate models in term of the estimated heritabilities for the two traits, although the $h^{2}$ of sea-age-corrected body length was somewhat lower $\left(h^{2}\right.$ of seaage-corrected body length $=0.06$ and $h^{2}$ of sea-age $=0.53$ in BV model 2; Table 3 ). The estimated genetic correlation between these traits was positive $\left(r_{G}=0.33\right)$ but the HPD 
intervals overlapped zero (Table 3), indicating that the $r_{G}$ was not significantly different from zero.

A power analysis showed that the Girnock data had sufficient power to detect $h^{2}>$ 0.22 with $>80 \%$ confidence with no inherent bias in the data-set (Fig.2).

\section{Testing for microevolutionary trends}

The temporal trend in estimated breeding values for the trait "sea-age corrected body-length" was estimated at $-0.0001 \log (\mathrm{cm}) /$ year (95\% quantiles: -0.0008 to 0.0004$)$. This trend in estimated breeding values was not statistically significantly negative, as only $67.4 \%$ of the posterior distribution of estimated temporal slopes was less than zero. The probability that this very small trend in estimated breeding values was more negative than one would expect based on random genetic drift was $63.3 \%$, again indicating a lack of any evidence for a microevolutionary response to selection. .

The temporal trend in estimated breeding values for the trait sea-age was estimated at -0.017 liability units per year (95\% quantiles: -0.053 to 0.009$)$. This trend in estimated breeding values was not statistically significantly negative, as only $81.8 \%$ of the posterior distribution of estimated temporal slopes was less than zero. The probability that this trend was more negative than one would expect based on random genetic drift was $74.3 \%$, again indicating a lack of solid evidence for a microevolutionary response to selection.

\section{DISCUSSION}

Our data from a well-studied, single, wild population of Atlantic salmon show that sea-age and body-length are both quite strongly heritable and, importantly, that the two traits are strongly genetically correlated. However, when sea-age is alternatively correlated to body- 
length within each sea-age class (i.e. sea-age corrected body-length), the genetic correlation is then not significantly different from zero, and nor is the $h^{2}$ for sea-age-corrected body-length, implying that individual variation in size within sea-ages does not have a heritable basis.

Most studies estimate quantitative genetic parameters in laboratory, or in the case of fish, aquaculture settings, which may not reveal much about evolutionary potential under wild natural conditions (Charmantier and Garant 2005). Our results thus add important general information regarding the potential for wild fish populations to respond to natural selection (or “unnatural selection”, c.f. Allendorf \& Hard 2009) and complement recent findings showing strong genetic components to age and size at maturity in Atlantic salmon (e.g. Ayllon et al. 2015, Barson et al. 2015, Lepais et al. 2017).

\section{Inheritance patterns}

Substantial amounts of additive genetic variance in sea-age were not entirely unexpected, given that recent studies of Atlantic salmon discovered several genetic loci underpinning variation in sea-age, including a single gene (VGLL3) that explains almost $40 \%$ of the total phenotypic variation (Ayllon et al. 2015, Barson et al. 2015). These studies used a very different approach - genome-wide associations combining data from a large number of populations across a broad geographic region - and homed-in on specific quantitative trait loci (QTL), whereas we followed a classical quantitative genetics approach that treats the underlying genetic architecture as a "black box" and focussed on a single population. The concordant inferences between studies conducted at very different scales using different methodologies - namely, that sea-age variation in wild Atlantic salmon populations has a strong genetic basis - points towards a general finding for the species. Studies of other fish species have also documented heritable differences in age-at-maturity within and among populations (e.g. mosquitofish Gambusia affini introduced to Hawaii, (Stearns 1983); guppies 
tshawytscha introduced to New Zealand, (Quinn et al. 2001). This raises interesting questions

429

430

431

432

433

434

435

436

437

regarding the evolutionary forces that maintain genetic variation in this key life-history trait,

which may include sex-dependent dominance (Barson et al. 2015), frequency-dependent selection and spatiotemporal variation in environmental selection pressures (Gurney et al. 2012). In this study we ignored potential sex-specific inheritance patterns, which is justified if inter-sex genetic correlations for our traits of interest are positive and high, but this assumption should be tested in future studies, given sufficient statistical power. It is also possible that the period of captive propagation might have had an influence on the results. The crossing protocol, which involved mating multiple males to females and vice versa, may have increased the number of links in the pedigree beyond that which might have occurred in the absence of captive propagation, in which case it could have afforded increased power and accuracy to our animal models. On the other hand, this represented a deviation from natural spawning behaviours and mate choice, which may have affected the expression of genetic variation (Pigliucci 2006), but we have no way of knowing a priori the direction and magnitude of such influences.

Despite these strong genetic effects, environmental influences clearly also play a role; in our study, for example, approximately half of the variation in sea-age was attributable to environmental variation, although some of this may have been due to non-additive genetic effects (dominance and epistasis) which we could not separate out with our pedigree structure (indeed, Barson et al. 2015 showed that dominance effects occur at the VGLL3 locus). To put this in practical terms, we observed over our study period that of the 114 offspring in total produced by matings between two MSW parents, 84 (74\%) of the resulting offspring themselves returned as MSW; thus a high heritability "biases" this probability towards "like producing like”. Friedland \& Hass (1996) found that the fraction of 1SW adult returns from a hatchery-dependent stock of Atlantic salmon was positively associated with late summer 
marine growth, implying that age-at-maturity responds plastically to marine environmental

454

455

456

457

458

459

460

461

462

463

464

465

466

467

468

469

470

471

472

473

474

475

476

477

conditions. The literature suggests that freshwater conditions may also affect the sea-age of anadromous Atlantic salmon, as implied by positive correlations between smolt size and the proportion of fish returning after 1SW (O’Connell and Ash 1993, Salminen 1997). Similarly, inverse relationships between freshwater age and ocean age have been found in wild steelhead trout Oncorhynchus mykis (Ward and Slaney 1988). However, if sub-populations are spatially structured, as in the North Esk in Scotland (Gurney et al., 2015; Bacon et al. 2012), with higher fractions of $1 \mathrm{SW}$ fish in lower parts of the catchment, where smolts also tend to get larger quicker (e.g. due to better growth at higher temperatures), then such correlations would arise from the spatial structuring alone, even if freshwater conditions have no causal effect on sea-age variation. Thus it remains unclear to what extent such patterns reflect plastic responses, spatial structuring, or genetic correlations among traits expressed at different life stages.

Genetic covariance among suites of growth-related and life-history traits have been demonstrated in rainbow/steelhead trout (Oncorhynchus mykiss) (Hecht et al. 2015) and brook charr (Salvelinus fontinalis) (Thériault et al. 2007), while some QTL for early male maturation status in Atlantic salmon also collocated with those affecting spring weights of juveniles (Lepais et al. 2017). We lacked individual-level data on freshwater or marine growth rates, and hence could not test explicitly for plastic effects of specific traits/cues on sea-age, nor could we test for genotype-by-environment interactions, which may be important here. Lepais et al. (2017) recently demonstrated that early male maturation in Atlantic salmon emerges as an interaction between individual growth rate (an environmentally-sensitive status trait) and a genetically variable maturation threshold (underpinned by at least three detectable QTL), using a powerful new approach called the "latent environmental threshold model" (LETM). It would be very interesting to apply the LETM approach to future studies of sea- 
age variation in Atlantic salmon or other anadromous fish; obtaining individual-level data on relevant status traits, such as post-smolt growth, that may act as cues for sea-age decisions will be challenging in many situations, but circuli spacing on scales could be used, for example (e.g. Friedland \& Hass 1996). Furthermore, it would be very interesting to dissect the mechanisms by which genetic variation in sea-age comes about; for example, Scottishorigin Atlantic salmon that eventually become MSW evidently use different oceanic feeding areas (e.g. the waters off Greenland) than those than adopt the 1SW life history (which are not recorded as going to Greenland, e.g. Malcolm et al. 2010), raising the intriguing possibility that genetic variation in migration routes and/or destinations might partially explain variation in sea-age, although the correlation between sea-age and migration patterns may not reflect any causal connection between these traits.

The significant positive genetic correlation we documented between sea-age and overall body-length is also consistent with the results of Barson et al. (2015), who documented pleiotropic effects of specific genomic regions on sea-age and size-at-maturity. Such pleiotropic effects are inevitable to a degree, in that alleles predisposing individuals towards later maturation at older sea-ages should also produce larger fish, given that Atlantic salmon keep growing the longer they remain at sea. A more surprising result was the fact that the genetic correlation between sea-age and body-length was so high $\left(r_{G}=0.96\right)$ as to imply that these are effectively the same trait at a genetic level. That does not mean, however, that body size is completely genetically-determined and indeed, in our case, it appears that individual variation in marine growth - a key determinant of body size at breeding - was predominantly environmental, rather than genetic, in origin. This is because sea-agecorrected body-length exhibited a low $h^{2}$ that did not differ significantly from zero (although we only had the statistical power to detect $h^{2}>$ ca. 0.22 , so a true $h^{2}$ of less than this cannot be ruled out). While this trait is not a direct measure of marine growth, Atlantic salmon put on 
most of their growth at sea (smolt sizes are very small, see URL4) and thus variation in marine growth rates and/or variation in coastal return-times must explain a large fraction of the variation in size of returning adults within each sea-age class. Smolt size could also indirectly account for some of the variation in adult size if, for example, larger smolts grow faster at sea (e.g. due to feeding advantages of initially larger size within shoals of postsmolts, which would set up a positive feedback).

A lack of (strong) genetic influences on marine growth is somewhat unexpected, given that genetic variation could operate via a range of mechanisms here; e.g. some genotypes could be better foragers, or target different prey types, or have different inherited marine migration pathways or destinations, that expose them to more or less growth opportunity, or be more efficient at converting food into somatic growth, etc. Moreover, return migration timing has been shown to have a heritable basis in Atlantic salmon (Stewart et al. 2002; Cauwelier et al. In Press) and other salmonids (Smoker et al. 1998, Quinn et al. 2000, O’Malley and Banks 2008, Kovach et al. 2012). This alone could produce corresponding genetic variation in body-length within sea-age classes, unless return periods were very short or if late-returning genotypes have lower marine growth rates than earlyreturning genotypes, such that final size differences among them are minimal. At present we can only speculate on this, as we do not have reliable information on coastal return-dates to estimate the $h^{2}$ of that trait and potential genetic correlations with body size, or indeed seaage. Our tentative conclusion at this point is that environmental drivers of body-length variation within each sea-age class are simply much larger in magnitude than any genetic influences.

$$
\text { Our tests for microevolution during the period 1990 2012 did not reveal any }
$$
genetically based trends towards reduced average sea-age, nor towards smaller body-size. However, over the longer period 1966 2016, Atlantic salmon from two Deeside streams (the 
528 Girnock and Baddoch) have shown a significant decline in MSW numbers whilst 1SW numbers remained stable, implying a significant decrease in average sea-age ratios, slightly reducing the average sea-age; they also showed concomitant downward trends in body size, which were coherent for both 1SW and MSW fish, (Glover et al. 2018 and pers comm). It may simply be that the phenotypic trends documented by Glover et al. are entirely driven by phenotypic plasticity, i.e. environmental influences on average sea-age and body size, rather than microevolutionary responses to any directional selection pressures that might have occurred over this period. Mortality pressures from both marine fisheries and freshwater angling were strong on Scottish Atlantic salmon during the period 1960 to 1990, which conceivably could have led to fisheries-induced selection (FIS) on, and subsequent evolution of, sea-age and/or body size. The data analysed in this study fall mainly into a period when marine fishery pressures were much reduced and freshwater angling pressures decreasing. As evolutionary recovery of phenotypic traits from FIS is expected to be much slower than declines caused by it (Heino et al. 2015), our findings with respect to microevolution could

542 simply reflect a period when any real changes were quite small and too low for our sample sizes to detect. Moreover, the current study was focussed on a shorter time period and involved smaller sample sizes than the Glover et al. study, and thus the power to detect a real but small-magnitude evolutionary response may have been limiting. A further complicating factor is that broad-scale climatic changes also occurred over this period, which may have

547 contributed to the observed phenotypic trends in Girnock salmon (Glover et al. 2018), either 548 via phenotypic plasticity, microevolution, or both. Given the apparently very low heritability 549 of body size within sea-ages, phenotypic plasticity - possibly driven by climate change represents the most parsimonious explanation for the observed length decreases in 1SW and MSW Girnock salmon. The fact that these trends are parallel between sea-ages, despite differing marine feeding zones, may point towards coherent climate effects acting across a 
large geographic scale, but factors other than climate may of course be at play. A clearer understanding of the relative roles of microevolution and plasticity and their environmental/anthropogenic drivers could be achieved by extending this pedigree study over a longer period to match the longer-term phenotypic data..

\section{ACKNOWLEDGEMENTS}

The opportunity for such genetic work was first realised by Alan Youngson, John Taggart and Eric Verspoor, whom we thank for initiating the sample-collection. John Taggart kindly provided tissue, and some DNA-extract aliquots, from the earlier years. We thank FFL field staff over two decades, particularly Iain Malcolm, Iain McLaren, Alastair Thorne, Mike Donaghy and Ross Glover, for collecting the data, scales and tissue samples. Alastair Thorne, Iain McLaren and Ross Glover read the scales and Aya Thorne prepared scales for DNA analysis. Iain Malcolm and Ross Glover collated and quality-controlled the biometric data. Iain Malcolm, Ross Glover and Stuart Middlemas made constructive comments on earlier versions of the manuscript. Data collection at the Girnock is funded by the Scottish Government, through Marine Scotland Science Freshwater Fisheries Laboratory under Service Level Agreement FW01t. TR was supported by a European Research Council (ERC) Starting Grant (639192), CRP by the Academy of Finland (grant numbers 302873, 307593). PMcG, PP and CB were supported by the Beaufort Marine Research award in Fish Population Genetics funded by the Irish Government under the Sea Change Programme. 
576 Author Contributions

577 The Girnock Atlantic Salmon Pedigree project was envisaged by PJB and organised by him 578 and PMcG, in collaboration with PP, JG and CRP. FFL contributed the tissue-samples and 579 biometric-data. DNA extraction and genotyping were undertaken at QUB by CB and PP. PP 580 and PJB merged the biometric and genotype data, PP undertook the parentage-assignments 581 and he and PJB thereby quality-controlled the original genotype scorings. PJB extracted and 582 quality-controlled the merged sub-set of data for this paper, including preliminary analyses.

583 TR fitted and interpreted the animal models. PP wrote the Methods and Results for parentage 584 analyses. TR and PJB wrote the Methods and Results for the quantitative genetic analyses 585 and an outline for the paper. All authors contributed to the final draft

586

587 


\section{REFERENCES}

Allendorf, F.W., and Hard, J.J. 2009. Human-induced evolution caused by unnatural selection through harvest of wild animals. Proc. Natl. Acad. Sci. 106(Supplement 1): 9987-9994.

Ayllon, F., Kjærner-Semb, E., Furmanek, T., Wennevik, V., Solberg, M.F., Dahle, G., Taranger, G.L., Glover, K.A., Almén, M.S., and Rubin, C.J. 2015. The vgll3 locus controls age at maturity in wild and domesticated Atlantic salmon (Salmo salar L.) males. PLoS Genet 11(11): e1005628.

Bacon, P.J., Gurney, W.S., McKenzie, E., Whyte, B., Campbell, R., Laughton, R., Smith, G., and MacLean, J. 2010. Objective determination of the sea age of Atlantic salmon from the sizes and dates of capture of individual fish. ICES J. Mar. Sci. 68(1): 130143.

Bacon, P.J., MacLean, J.C., Malcolm, I.A., and Gurney, W.S.C. 2012. Ova fecundity in Scottish Atlantic salmon Salmo salar: predictions, selective forces and causal mechanisms. J. Fish Biol. 81(3): 921-938.

Bacon, P.J., Palmer, S.C.F., MacLean, J.C., Smith, G.W., Whyte, B.D.M., Gurney, W.S.C., and Youngson, A.F. 2009. Empirical analyses of the length, weight, and condition of adult Atlantic salmon on return to the Scottish coast between 1963 and 2006. ICES J. Mar. Sci. 66(5): 844-859.

Barson, N.J., Aykanat, T., Hindar, K., Baranski, M., Bolstad, G.H., Fiske, P., Jacq, C., Jensen, A.J., Johnston, S.E., and Karlsson, S. 2015. Sex-dependent dominance at a single locus maintains variation in age at maturity in salmon. Nature. 528(7582): 405408.

Brommer, J.E., Merilä, J., and Kokko, H. 2002. Reproductive timing and individual fitness. Ecol. Lett. 5(6): 802-810. 
Butler, D., Cullis, B.R., Gilmour, A.R., and Gogel, B.J. 2015. Mixed models for S language environments. ASReml-R reference manual. ASReml estimates variance components under a general linear mixed model by residual likelihood (REML). Version 3.0. Queensland, Australia.

Cauwelier, E., Gilbey, J., Sampayo, J., Stradmeyer, L. \& Middlemas, S. (In press). Identification of a single genomic region associated with seasonal river return timing in adult Scottish Atlantic salmon (Salmo salar L.) identified using a genome-wide association study. Can. J. Fish. Aq. Sci.

Carlson, S.M., and Seamons, T.R. 2008. A review of quantitative genetic components of fitness in salmonids: implications for adaptation to future change. Evol. Appl. 1(2): $222-238$.

Charlesworth, B. 1994. Evolution in age-structured populations. Cambridge University Press Cambridge.

Charmantier, A., and Garant, D. 2005. Environmental quality and evolutionary potential: lessons from wild populations. Proc. R. Soc. B Biol. Sci. 272(1571): 1415-1425.

Clutton-Brock, T., and Sheldon, B.C. 2010. Individuals and populations: the role of longterm, individual-based studies of animals in ecology and evolutionary biology. Trends Ecol. Evol. 25(10): 562-573.

Dickerson, B.R., Willson, M.F., Bentzen, P., and Quinn, T.P. 2005. Heritability of life history and morphological traits in a wild pink salmon population assessed by DNA parentage analysis. Trans. Am. Fish. Soc. 134(5): 1323-1328.

Enberg, K., Jorgensen, C., Dunlop, E. S., Heino, M. \& Dieckmann, U. 2009. Implications of fisheries-induced evolution for stock rebuilding and recovery. Evol. Appl. 2: 394-414.

Gjerde, B. 1984. Response to individual selection for age at sexual maturity in Atlantic salmon. Aquaculture 38(3): 229-240. 
Glover, R. S., Fryer, R.J., Bacon, P.J., Soulsby, C., Malcolm, I.A. 2018. Do trends in the size of wild female Atlantic salmon have a substantial effect on egg deposition? Fish. Man. and Ecol. 25: 158-161. https://doi.org/10.1111/fme.12273

Gurney, W.S., Bacon, P.J., Speirs, D.C., McGinnity, P., and Verspoor, E. 2012. Sea-age variation in maiden Atlantic salmon spawners: phenotypic plasticity or genetic polymorphism? Bull. Math. Biol. 74(3): 615-640.

Gurney, W.S.C., Bacon, P.J., Malcolm, I.A., MacLean, J.C., and Youngson, A.F. 2015. Atlantic salmon (Salmo salar) population as discerned for an eastern Scottish river. Scott. Mar. Freshw. Sci. 6(12): 1-72. doi:10.7489/1662-.

Hadfield, J.D. 2010. MCMC methods for multi-response generalized linear mixed models: the MCMCglmm R package. J. Stat. Softw. 33(2): 1-22.

Hadfield, J.D., Wilson, A.J., Garant, D., Sheldon, B.C., and Kruuk, L.E. 2010. The misuse of BLUP in ecology and evolution. Am. Nat. 175(1): 116-125.

Hankin, D.G., Nicholas, J.W., and Downey, T.W. 1993. Evidence for inheritance of age of maturity in chinook salmon (Oncorhynchus tshawytscha). Can. J. Fish. Aquat. Sci. 50(2): $347-358$.

Harvey, A. C., Tang, Y., Wennevik, V., Skaala, Ø. \& Glover, K. A. 2017. Timing is everything: Fishing- season placement may represent the most important anglinginduced evolutionary pressure on Atlantic salmon populations. Ecol. and Evol. 7: 7490-7502.

Hecht, B.C., Hard, J.J., Thrower, F.P., and Nichols, K.M. 2015. Quantitative genetics of migration-related traits in rainbow and steelhead trout. G3 Genes Genomes Genet. 5(5): 873-889.

Heino, M., and Kaitala, V. 1999. Evolution of resource allocation between growth and reproduction in animals with indeterminate growth. J. Evol. Biol. 12(3): 423-429. 
Heino, M., Diaz Pauli, B., and Dieckmann, U. 2015. Fisheries-induced evolution. Ann. Rev. Ecol. Evol. Syst., 46: 461-480.

Hutchings, J.A. and Jones, M.E., 1998. Life history variation and growth rate thresholds for maturity in Atlantic salmon, Salmo salar. Can. J. Fish. Aq. Sci., 55(S1): 22-47.

Johnston, S.E., Orell, P., Pritchard, V.L., Kent, M.P., Lien, S., Niemelä, E., Erkinaro, J., and Primmer, C.R. 2014. Genome-wide SNP analysis reveals a genetic basis for sea-age variation in a wild population of Atlantic salmon (Salmo salar). Mol. Ecol. 23(14): 3452-3468.

Kause, A., Ritola, O., Paananen, T., Mäntysaari, E., and Eskelinen, U. 2003. Selection against early maturity in large rainbow trout Oncorhynchus mykiss: the quantitative genetics of sexual dimorphism and genotype-by-environment interactions. Aquaculture 228(1): 53-68.

Keenan, K., Bradley, C.R., Magee, J.J., Hynes, R.A., Kennedy, R.J., Crozier, W.W., Poole, R., Cross, T.F., McGinnity, P., and Prodöhl, P.A. 2013a. Beaufort trout MicroPlex: a high-throughput multiplex platform comprising 38 informative microsatellite loci for use in resident and anadromous (sea trout) brown trout Salmo trutta genetic studies. J. Fish Biol. 82(6): 1789-1804. doi:10.1111/jfb.12095.

Keenan, K., McGinnity, P., Cross, T.F., Crozier, W.W., and Prodöhl, P.A. 2013b. diveRsity: An $\mathrm{R}$ package for the estimation and exploration of population genetics parameters and their associated errors. Methods Ecol. Evol. 4(8): 782-788.

Klemetsen, A., P-A. Amundsen, J. B. Dempson, B. Jonsson, N. Jonsson, M. F. O'Connell, and Mortensen, E. 2003. Atlantic salmon Salmo salar L., brown trout Salmo trutta L. and Arctic charr Salvelinus alpinus (L.): a review of aspects of their life histories." Ecol. Fresh. Fish 12(1): 1-59. 
687

688

689

690

691

692

693

694

695

696

697

698

699

700

701

702

703

704

705

706

707

708

709

710

711

Kovach, R.P., Gharrett, A.J., and Tallmon, D.A. 2012. Genetic change for earlier migration timing in a pink salmon population. Proc. R. Soc. Lond. B Biol. Sci. 279(1743): 3870-3878.

Kuparinen, A. \& Hutchings, J. A. 2017. Genetic architecture of age at maturity can generate divergent and disruptive harvest-induced evolution. Phil. Trans. Roy. Soc. B: Biological Sciences 372 (1712): 20160035.

Lepais, O., Manicki, A., Glise, S., Buoro, M., and Bardonnet, A. 2017. Genetic architecture of threshold reaction norms for male alternative reproductive tactics in Atlantic salmon (Salmo salar L.). Sci. Rep. 7.

Malcolm, I. A., Godfrey, J., and Youngson, A. F. 2010. Review of migratory routes and behaviour of Atlantic salmon, sea trout and European eel in Scotland's coastal environment: implications for the development of marine renewables. Scottish Marine and Freshwater Science, 1(14): 1-72.

Morrissey, M.B., and Ferguson, M.M. 2011. A test for the genetic basis of natural selection: an individual-based longitudinal study in a stream-dwelling fish. Evolution 65(4): 1037-1047.

Munday, P.L., Warner, R.R., Monro, K., Pandolfi, J.M., and Marshall, D.J. 2013. Predicting evolutionary responses to climate change in the sea. Ecol. Lett. 16(12): 1488-1500.

Nævdal, G. 1983. Genetic factors in connection with age at maturation. Aquaculture 33(1): $97-106$

Naish, K.A., and Hard, J.J. 2008. Bridging the gap between the genotype and the phenotype: linking genetic variation, selection and adaptation in fishes. Fish Fish. 9(4): 396-422.

O’Connell, M.F., and Ash, E.G.M. 1993. Smolt size in relation to age at first maturity of Atlantic salmon (Salmo salar): the role of lacustrine habitat. J. Fish Biol. 42(4): 551569. 
Olafsson, K., Hjorleifsdottir, S., Pampoulie, C., Hreggvidsson, G.O., and Gudjonsson, S. 2010. Novel set of multiplex assays (SalPrint15) for efficient analysis of 15 microsatellite loci of contemporary samples of the Atlantic salmon (Salmo salar). Mol. Ecol. Resour. 10(3): 533-537.

O'Malley, K.G., and Banks, M.A. 2008. A latitudinal cline in the Chinook salmon (Oncorhynchus tshawytscha) Clock gene: evidence for selection on PolyQ length variants. Proc. R. Soc. Lond. B Biol. Sci. 275(1653): 2813-2821.

Pigliucci, M. 2006. Genetic variance-covariance matrices: a critique of the evolutionary quantitative genetics research program. Biol. and Phil. 21(1): 1-23.

Quinn, T.P., Kinnison, M.T., and Unwin, M.J. 2001. Evolution of chinook salmon (Oncorhynchus tshawytscha) populations in New Zealand: pattern, rate, and process. Genetica 112(1): 493-513.

Quinn, T.P., Unwin, M.J., and Kinnison, M.T. 2000. Evolution of temporal isolation in the wild: genetic divergence in timing of migration and breeding by introduced chinook salmon populations. Evolution 54(4): 1372-1385.

Reed, T.E., Prodöhl, P., Hynes, R., Cross, T., Ferguson, A., and McGinnity, P. 2015. Quantifying heritable variation in fitness-related traits of wild, farmed and hybrid Atlantic salmon families in a wild river environment. Heredity. 115(2): 173-184.

Reznick, D.A., Bryga, H., and Endler, J.A. 1990. Experimentally induced life-history evolution in a natural population. Nature 346(6282): 357-359.

Roff, D.A. 2002. Life History Evolution. 1 edition. Sinauer Associates, Inc., Sunderland, Mass.

Salminen, M. 1997. Relationships between smolt size, postsmolt growth and sea age at maturity in Atlantic salmon ranched in the Baltic Sea. J. Appl. Ichthyol. 13(3): 121130. 
Serbezov, D., Bernatchez, L., Olsen, E.M., and Vøllestad, L.A. 2010. Quantitative genetic parameters for wild stream-living brown trout: heritability and parental effects. J. Evol. Biol. 23(8): 1631-1641.

Smoker, W.W., Gharrett, A.J., and Stekoll, M.S. 1998. Genetic variation of return date in a population of pink salmon: a consequence of fluctuating environment and dispersive selection. Alsk. Fish. Res. Bull. 5(1): 46-54.

Stearns, S.C. 1983. The evolution of life-history traits in mosquitofish since their introduction to Hawaii in 1905: rates of evolution, heritabilities, and developmental plasticity. Am. Zool. 23(1): 65-75.

Stearns, S.C. 1992. The evolution of life histories. Oxford University Press Oxford.

Stewart, D.C., Smith, G.W., and Youngson, A.F. 2002. Tributary-specific variation in timing of return of adult Atlantic salmon (Salmo salar) to fresh water has a genetic component. Can. J. Fish. Aquat. Sci. 59(2): 276-281.

Sydeman, W.J., Poloczanska, E., Reed, T.E., and Thompson, S.A. 2015. Climate change and marine vertebrates. Science 350(6262): 772-777.

Taggart, J.B. 2007. FAP: an exclusion-based parental assignment program with enhanced predictive functions. Mol. Ecol. Resour. 7(3): 412-415.

Taggart, J.B., McLaren, I.S., Hay, D.W., Webb, J.H., and Youngson, A.F. 2001. Spawning success in Atlantic salmon (Salmo salar L.): a long-term DNA profiling-based study conducted in a natural stream. Mol. Ecol. 10(4): 1047-1060.

Thériault, V., Garant, D., Bernatchez, L., and Dodson, J.J. 2007. Heritability of life-history tactics and genetic correlation with body size in a natural population of Brook Charr (Salvelinus fontinalis). J. Evol. Biol. 20(6): 2266-2277.

Tipping, J.M. 1991. Management briefs: heritability of age at maturity in steelhead. North Am. J. Fish. Manag. 11(1): 105-108. 
Ward, B.R., and Slaney, P.A. 1988. Life history and smolt-to-adult survival of Keogh River steelhead trout (Salmo gairdneri) and the relationship to smolt size. Can. J. Fish. Aquat. Sci. 45(7): 1110-1122.

Yano, A., Guyomard, R., Nicol, B., Jouanno, E., Quillet, E., Klopp, C., Cabau, C., Bouchez, O., Fostier, A., and Guiguen, Y. 2012. An immune-related gene evolved into the master sex-determining gene in rainbow trout, Oncorhynchus mykiss. Curr. Biol. 22(15): 1423-1428.

Yano, A., Nicol, B., Jouanno, E., Quillet, E., Fostier, A., Guyomard, R., and Guiguen, Y. 2013. The sexually dimorphic on the Y-chromosome gene (sdY) is a conserved malespecific Y-chromosome sequence in many salmonids. Evol. Appl. 6(3): 486-496.

\section{Websites cited:}

URL1: http://www.gov.scot/Topics/marine/Salmon-Trout-

$\underline{\text { Coarse/Freshwater/Monitoring/Traps }}$

URL2: http://www.gov.scot/Topics/marine/Salmon-Trout-

Coarse/Freshwater/Monitoring/Traps/AdultReturnsPopStatus

URL3: http://data.marine.gov.scot/dataset/girnock-and-baddoch-adult-returns-traps

Citation: Glover, R., Malcolm, I. 2015. Girnock and Baddoch: Adult Returns to the Traps.

DOI: $10.7489 / 1588-1$

URL4: http://www.gov.scot/Topics/marine/Salmon-Trout-

Coarse/Freshwater/Monitoring/Traps/JuvenileEmigrants

Citation: Glover, R., Malcolm, I. 2015. Girnock and Baddoch: Emigrant Numbers by Year of Emigration. DOI: 10.7489/1017-1 
786 Appendices:

787 Appendix A:

788

A.1 Microsatellite marker information

789

A.2 Summary sample statistics per locus / cohort

790 Appendix B:

791

B.1 Details on the reconstructed pedigree

792

B.2 Full details on the estimation procedures for the quantitative genetic parameters

793

B.3 Power analyses for heritability estimation

794

B.4 Testing for microevolutionary trends

795 
796 Table 1 Summary of annual sample sizes of adult Atlantic salmon within the reconstructed

797 Girnock pedigree. Column 2 shows the total number of individual fish spawning in that year

798 (Column 1) that appeared either as parents or offspring within "parent-offspring trios" (where

799 a trio represents one offspring and both its genetically-assigned parents). For example, an

800 adult returning in 1996 could be recorded as being in a trio in that year (i) because it mated

801 with another fish in that year and produced at least one surviving offspring that itself was

802 DNA-sampled as a spawning adult (e.g. six years later in 2002); (ii) because it was itself

803 assigned two parents (which might have spawned and been DNA-sampled in 1991, for

804 example), or (iii) for both reasons (i.e. some fish appear in the pedigree as both offspring and

805 parents). Columns 3 and 4 break Column 2 down by sex. Column 5 specifies how many of

806 the fish enumerated in Column 2 were themselves assigned two parents, while Column 6

807 specifies how many were assigned no parents.

808

809

810

811

812

813

814

815

816 


\begin{tabular}{|c|c|c|c|c|c|}
\hline $\begin{array}{c}\text { Adult Return } \\
\text { Year }\end{array}$ & Total & Females & Males & $\begin{array}{c}\text { Number with } \\
\text { both }^{\dagger} \text { parents } \\
\text { known }\end{array}$ & $\begin{array}{c}\text { Number with } \\
\text { neither parents } \\
\text { known }\end{array}$ \\
\hline 1991 & 8 & 5 & 3 & $0^{\dagger \dagger}$ & 8 \\
\hline 1992 & 9 & 4 & 5 & 0 & 9 \\
\hline 1993 & 6 & 3 & 3 & 0 & 6 \\
\hline 1994 & 2 & 1 & 1 & 0 & 2 \\
\hline 1995 & 13 & 7 & 6 & 0 & 13 \\
\hline 1996 & 12 & 8 & 4 & 7 & 5 \\
\hline 1997 & 6 & 3 & 3 & 3 & 3 \\
\hline 1998 & 10 & 6 & 4 & 6 & 4 \\
\hline 1999 & 15 & 6 & 9 & 5 & 10 \\
\hline 2000 & 28 & 11 & 17 & 8 & 20 \\
\hline 2001 & 10 & 6 & 4 & 5 & 5 \\
\hline 2002 & 11 & 3 & 8 & 4 & 7 \\
\hline 2003 & 13 & 5 & 8 & 5 & 8 \\
\hline 2004 & 51 & 28 & 23 & 9 & 42 \\
\hline 2005 & 40 & 25 & 15 & 14 & 26 \\
\hline 2006 & 46 & 28 & 18 & 9 & 37 \\
\hline 2007 & 23 & 13 & 10 & 5 & 18 \\
\hline 2008 & 19 & 7 & 12 & 14 & 5 \\
\hline 2009 & 37 & 14 & 23 & 37 & 0 \\
\hline 2010 & 60 & 25 & 35 & 60 & 0 \\
\hline 2011 & 65 & 42 & 23 & 65 & 0 \\
\hline Grand totals: & 484 & 250 & 234 & 256 & 228 \\
\hline
\end{tabular}

817

$818 \dagger$ Note that this pedigree study focussed only on "full trios", i.e. cases where both parents of a given offspring 819 were assigned. An unknown fraction of offspring each year are sired by precociously maturing males, which are 820 not DNA-sampled and therefore cannot be assigned as true fathers, but the numbers here refer only to full 821 parent-offspring trios.

$822 \dagger$ †ote that prior to 1996, the parents of sampled spawning adults were not discernible as these parents would 823 have themselves spawned prior to 1991, when DNA samples were not available. 
Table 2 Results of the univariate animal models. The values for adult body-length are on the

831 natural logarithm scale, while the values for sea-age-at-maturity are on the underlying

832 liability scale from the probit model (note the residual variance was fixed at 1). The intercept

833 refers to the fixed effect of the reference sex, females. HPD = highest posterior density.

\begin{tabular}{ccccc}
\hline Model & Parameter & Mean & $\begin{array}{c}\text { Lower HPD } \\
\text { interval }\end{array}$ & $\begin{array}{c}\text { Upper HPD } \\
\text { interval }\end{array}$ \\
\hline (UV model 1) & Intercept (females) & 4.197 & 4.173 & 4.2223 \\
Univariate for & Sex: males & -0.072 & -0.090 & -0.049 \\
adult body- & Additive genetic variance $V_{A}$ & 0.0039 & 0.0016 & 0.0062 \\
length & Maternal variance $V_{M}$ & 0.0014 & 0.0002 & 0.0029 \\
& Year variance $V_{M}$ & 0.0016 & 0.0004 & 0.0033 \\
& Residual variance $V_{R}$ & 0.0078 & 0.0058 & 0.0101 \\
& Heritability $h^{2}$ & 0.265 & 0.125 & 0.414 \\
$(U V$ model 2) & & & & \\
Univariate for & Intercept (females) & 0.000 & -0.0148 & 0.0136 \\
sea-age- & Sex: males & 0.0179 & -0.0048 & 0.0307 \\
corrected body & Additive genetic variance $V_{A}$ & 0.0008 & 0.0003 & 0.0015 \\
length & Maternal variance $V_{M}$ & 0.0008 & 0.0003 & 0.0015 \\
& Year variance $V_{M}$ & 0.0005 & 0.0001 & 0.0010 \\
& Residual variance $V_{R}$ & 0.0037 & 0.0030 & 0.0045 \\
$(U V$ model 3) & Heritability $h^{2}$ & 0.140 & 0.044 & 0.261 \\
Univariate for & & & & \\
sea-age-at- & Intercept (females) & 2.207 & 1.299 & 3.363 \\
maturity & Sex: males & -2.511 & -3.647 & -1.539 \\
& Additive genetic variance $V_{A}$ & 2.580 & 0.114 & 6.143 \\
& Maternal variance $V_{M}$ & 0.212 & 0.000 & 0.809 \\
& Year variance $V_{M}$ & 0.937 & 0.081 & 2.158 \\
& Residual variance $V_{R}$ & 1.000 & 1.000 & 1.000 \\
& Heritability $h^{2}$ & 0.511 & 0.267 & 0.734 \\
\hline
\end{tabular}

834

835

836

837

838

839

840

841

842

843 
845 Table 3 Results of the bivariate animal models of (1) adult body-length and sea-age (binary

846 trait), and (2) sea-age-corrected body length and sea-age. The values for adult body-length

847 and sea-age-corrected body length are on the natural logarithm scale, while the values for

848 sea-age are on the underlying liability scale from the probit model (note that $V_{R}$ for sea-age

849 was fixed at 1). The fixed effects are not reported as they mirror the findings of the univariate

850 models.

\begin{tabular}{ccccc}
\hline Model & Parameter & Mean & $\begin{array}{c}\text { Lower HPD } \\
\text { interval }\end{array}$ & $\begin{array}{c}\text { Upper HPD } \\
\text { interval }\end{array}$ \\
\hline$(B V$ model 1$)$ & $V_{A}$ for body length & 0.0042 & 0.0019 & 0.0065 \\
Bivariate for & $V_{A}$ for sea-age & 1.0914 & 0.1436 & 2.2986 \\
adult body- & Additive genetic covariance $C O V_{A}$ & 0.0633 & 0.0171 & 0.1157 \\
length and & $V_{R}$ for body length & 0.0116 & 0.0095 & 0.0138 \\
sea-age & $V_{R}$ for sea-age & 1.0000 & 1.0000 & 1.0000 \\
& Residual covariance $C O V_{R}$ & 0.0635 & 0.0471 & 0.0791 \\
& Heritability $h^{2}$ for body length & 0.2637 & 0.1261 & 0.3878 \\
& Heritability $h^{2}$ for sea-age & 0.4823 & 0.2174 & 0.7284 \\
& Genetic correlation $r_{G}$ & 0.9551 & 0.9096 & 0.9879 \\
$(B V$ model 2$)$ & Environmental correlation $r_{E}$ & 0.5893 & 0.4586 & 0.6834 \\
Bivariate for & & & & 0.0007 \\
adult body- & $V_{A}$ for body length within sea-ages & 0.0004 & 0.0002 & 2.2986 \\
length within & $V_{A}$ for sea-age & 1.5715 & 0.1436 & 0.0256 \\
sea-ages, and & Additive genetic covariance $C O V_{A}$ & 0.0079 & -0.0077 & 0.0078 \\
sea-age & $V_{R}$ for body length within sea-ages & 0.0069 & 0.0061 & 1.0000 \\
& $V_{R}$ for sea-age & 1.0000 & 1.0000 & 0.0976 \\
& Heritability $h^{2}$ for body length within sea-ages & 0.0560 & 0.0295 & 0.8495 \\
\hline & Heritability $h^{2}$ for sea-age & 0.5347 & 0.2316 & 0.7205 \\
\hline
\end{tabular}

851

852

853

854

855

856

857

858

859

860 


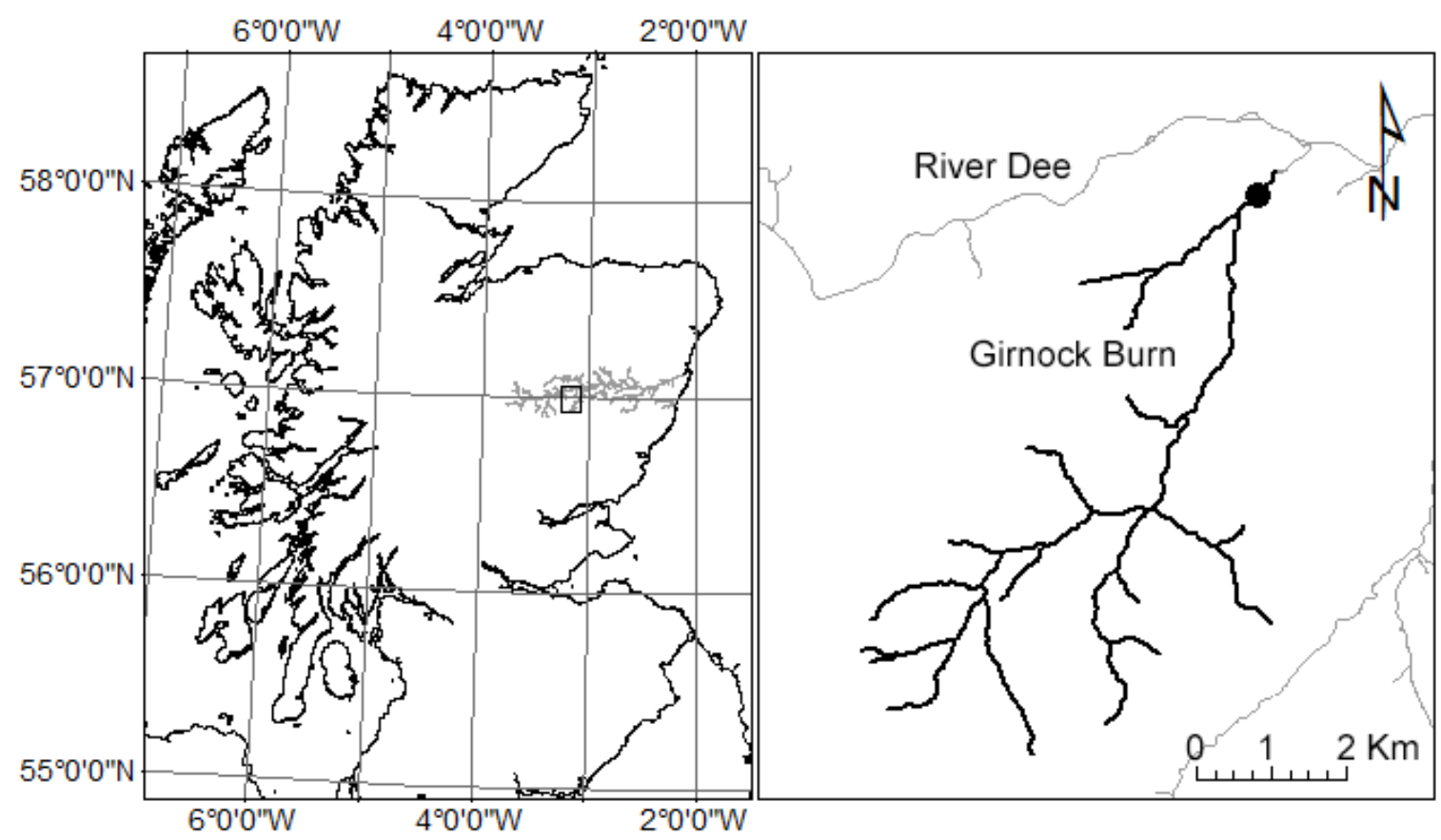

866

867 Fig.1 Map of the Girnock Burn study system, a tributary of the River Dee, Aberdeenshire,

868 Scotland.

869

870

871

872

873

874

875 


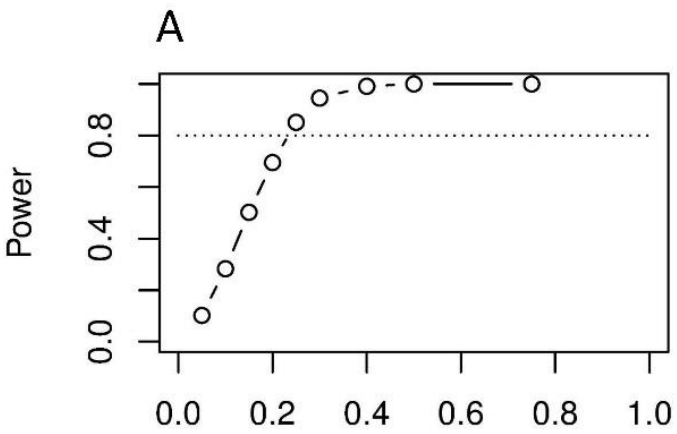

Simulated heritability

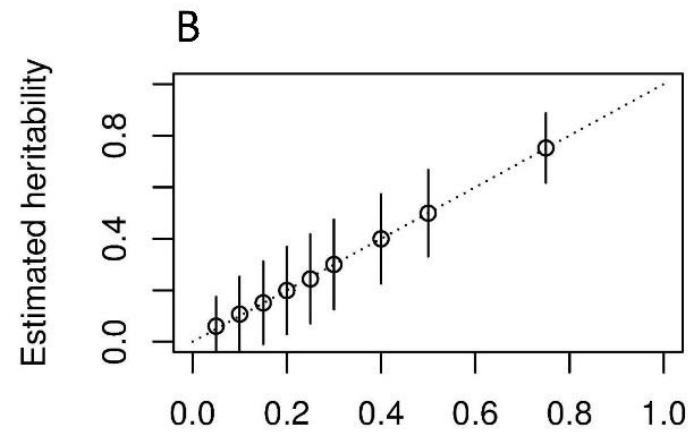

Simulated heritability

878 Fig.2 Power analysis for heritability estimation for an arbitrary trait given the observed

879 pedigree and phenotypic data structure, with statistical power (A) and estimated heritability

880 (mean plus 95\% confidence intervals, B) plotted against simulated heritability. Dotted line in

881 A corresponds to a power of $80 \%$; dotted line in B shows the 1:1 line. 